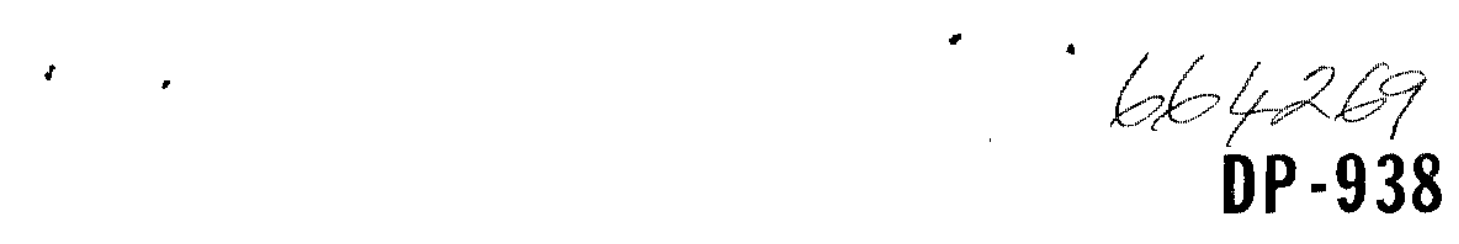

\title{
A COMPUTER CODE FOR ONE-GROUP FLUX CALCULATIONS IN THREE DIMENSIONS
}

\author{
J. C. English
}

SRL

RECORO COPY

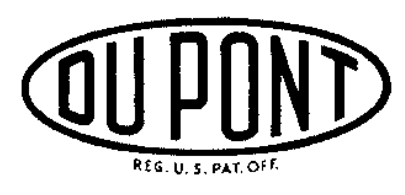

Savannah River Laboratory

Aiken, South Carolina 


\section{LEG A L NOT I CE}

This repart was prepared as an account of Government sponsored work. Neither the United States, nor the Commission, nor any person acting on behalf of the Commission:

A. Makes any warranty or representation, expressed or implied, whth respect to the accuracy, completeness, or usefulness of the information contained in this report, or that the use of any information, apparatus, method, or process disclosed in this report may not infringe privately owned rights; or

B. Assumes any liablities with respect to the use of, or for damages resulting from the use of any information, apparatus, method, or process disclosed in this report.

As used in the above, "person acting on behalf of the Commission" includes any employee or contractor of the Commission, or employee of such contractor, to the extent that such employee or contractor of the Commission, or employee of such contractor prepares, disseminates, or provides access to, any information pursuant to his employment or contract with the Commission, or his employment with such contractor.

Printed in USA. Price $\$ 2.00$

Avallable from the Clearinghouse for Federal Sclentific and Technical Information, National Bureau of Standards,

U. S. Department of Commerce, Springfield, Virginia 


\title{
$\underset{D P-938}{664269}$
}

Mathematics and Computers

(TID-4500, 4lst Ed.)

A COMPUTER CODE FOR ONE-GROUP

FLUX CALCULATIONS IN THREE DIMENSIONS

\author{
by \\ Jullus C. English
}

Approved by

J. W. Wade, Research Manager

Applied Mathematics Division

May 1965

\footnotetext{
E. I. DU PONT DE NEMOURS \& COMPANY

SAVANNAH RIVER LABORATORY

AIKEN, SOUTH CAROLINA

CONTRACT AT(07.2)-1 WITH THE

UNITBD STATES ATOMIC BNERGY COMMISSION
} 


\section{ABSTRACT}

A computer code, 3D-HEXLAX, has been written in FORTRAN II to solve the one-group neutron diffusion equation over a triangular network of points in two- or three-space dimensions by relaxation methods. The network can contain up to 817 grid points in the $R-\theta$ plane and up to 16 horizontal levels. Typlcal computation time on the IBM 704 ranges from 43 to 255 minutes as the number of grid points vary from 3,500 to 13,000 . 


\section{CONTENTS}

Page

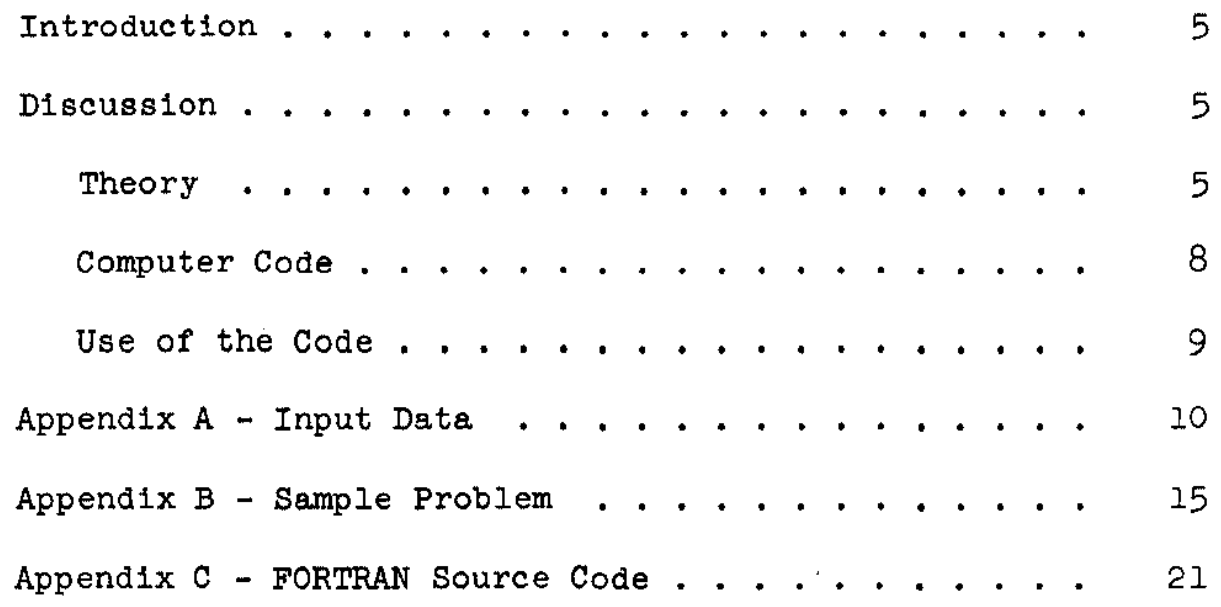


$-4-$ 
A COMPUTER CODE FOR ONE-GROUP

FLUX CALCULATIONS IN THREE DIMENSIONS

\section{INTRODUCTION}

Numerous studies requiring calculation of the over-all flux distribution in the Savannah River reactors have been made using one-group diffusion theory. Buckling values for the various reactor regions are measured experimentally and are then used in the diffusion equation to calculate the flux distribution. This simplified method has been used successfully to determine control rod positions required for shaping the axial and radial power distribution. At the Savannah River Laboratory one-group diffusion theory codes have been developed with two-space dimensions allowed: the UNCLE code for calculation in the R-Z plane and the HEXLAX code for the $R-\theta$ plane.

As reactor loadings have become more varied, there has been an increased need for performing flux calculations in three-space dimensions. This report describes a code, 3D-HEXLAX, that has been developed to meet this need.

\section{Theory}

\section{DISCUSSION}

The requirement is to solve the neutron diffusion equation $\nabla^{2} \phi+B^{2} \phi=0$ in both two- and three-space dimensions. Only right cylindrical reactors with either circular or hexagonal cross sections will be considered. If the reactor is infinite in the direction of its axis, then the equation becomes two-dimensional; otherwise 1 it is a three-dimensional problem.

The solution to the diffusion equation is obtained by relaxation over a network of grid points. A finite reactor with hexagonal cross section is assumed. If the reactor has a circular cross section, then 1 it is approximated by truncating the hexagon at its vertices. A number of grid points, $N$, is chosen for an edge of the hexagon whose length is $L_{1}$. A network is then lald over the hexagonal cross section with a grid spacing $\delta_{1}=\frac{L_{1}}{N-1}$. If $N$ is 2 , the grid is

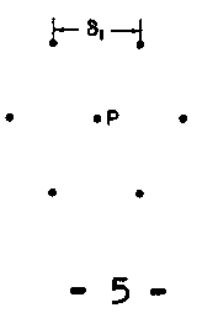


If $\mathrm{N}$ is greater than 2, then all interlor points of the grid have six points adjacent to them as point $P$ does above.

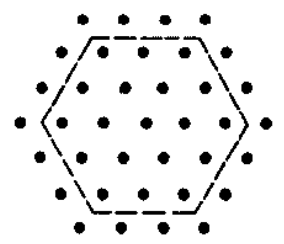

All interior points (inside dotted line) have six close neighbors. The central point and its adjacent neighbors are labeled as follows:

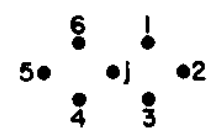

$\nabla{ }^{c_{j}}$ may be approximated in the plane by $\frac{2}{3 \delta_{l}^{2}}\left(\sum_{k=1}^{6} \phi_{k}-6 \phi_{j}\right)$.

The reactor can be subdivided into L-l horizontal slices by defining $L$ uniformly spaced planes normal to the axis of the reactor where the first and $L^{\text {th }}$ planes are the planes of the bottom and top of the reactor, respectively. vertical spacing between planes $\delta_{2}=\frac{\text { Height }}{\mathrm{L}-1}$. In the vertical dimension, $\nabla^{2} \phi=\frac{\partial^{2} \phi}{\partial z^{2}}$ and this is approximated by $\frac{1}{\delta_{2}^{2}}\left(\phi_{1+1}+\phi_{1-1}-2 \phi_{1 j}\right)$.

$\phi_{\text {if }}$ is the reference flux at level 1 and point $j$

Since the reactor considered is a right cylinder, then the approximation in three dimensions for $\nabla^{2} \phi_{1 j}$ is

$$
\nabla^{2} \phi_{i j}=\frac{2}{3 \delta_{1}^{2}}\left(\sum_{k=1}^{6} \phi_{i k}-6 \phi_{1 j}\right)+\frac{1}{\delta_{2}^{2}}\left(\phi_{1+1}+\phi_{1-1}-2 \phi_{i j}\right)
$$

Then substituting the expression for $\nabla^{2}{ }_{i f}$ into the diffusion equation and solving for $\phi_{i j}$ yield

$$
\Phi_{1 j}=\frac{\delta_{2}^{2} \sum_{k=1}^{6} \phi_{i k}+\frac{3}{2} \delta_{1}^{2}\left(\phi_{1+1, j}+\phi_{1-1, j}\right)}{6 \delta_{2}^{2}+3 \delta_{1}^{2}-\frac{3}{2} \delta_{1}^{2} \delta_{2}^{2} B_{1 j}^{2}}
$$


where

$$
\begin{aligned}
& \phi=\text { neutrons } / \mathrm{cm}^{2} / \mathrm{sec} \\
& B^{2}=\text { buckling, } \mathrm{cm}^{-2}
\end{aligned}
$$

After each iteration the flux is normalized so that the average flux in the central region of the reactor is approximately 100. The normalization factor, $R$, is

$$
R=\frac{100 N_{1}+50 N_{p}}{\sum_{1, j} \phi_{1 j}}
$$

where

$$
\begin{aligned}
& \mathrm{N}_{1}=\text { number of interior grid points } \\
& \mathrm{N}_{\mathrm{p}}=\text { number of peripheral grid points }
\end{aligned}
$$

To speed convergence the difference in flux between successive iterations is extrapolated by a factor $\gamma$.

With this extrapolation and with the renormalization factor, the flux equation is

$\phi_{1 J}=R \phi_{1 J}+\gamma\left\{\frac{\delta_{2}^{2}\left[\phi_{1, J-1}+\phi_{1, J 2}+\phi_{1, J 1}+R\left(\phi_{1, J+1}+\phi_{1, J 4}+\phi_{1, J 3}\right)\right]+\frac{3}{2} \delta_{1}^{2}\left[\phi_{1-1, j}+R \Phi_{1+1, j}\right]}{6 \delta_{2}^{2}+3 \delta_{1}^{2}-\frac{3}{2} \delta_{1}^{2} \delta_{2}^{2}\left(B_{1 J}^{2}+\Delta B^{2}\right)}-R \phi_{1 J}\right\}$

where

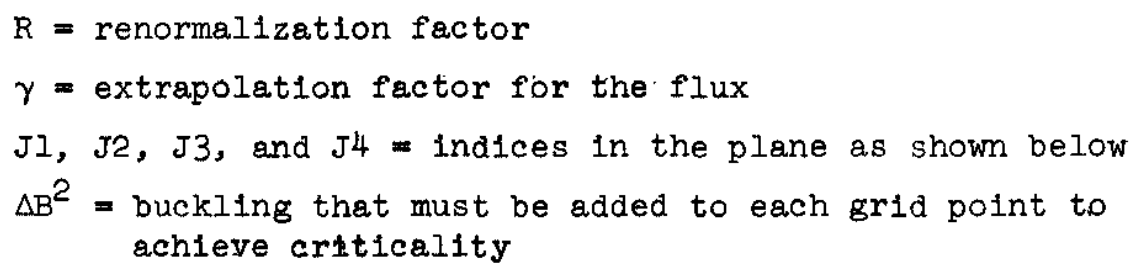
achieve criticality

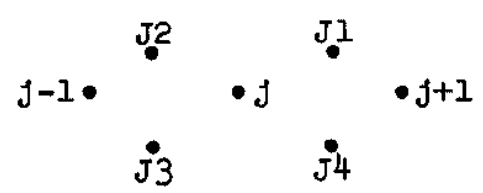

This is the expression which is used in the code for the three-dimensional solution. 
For two-dimensional problems, the expression reduces to

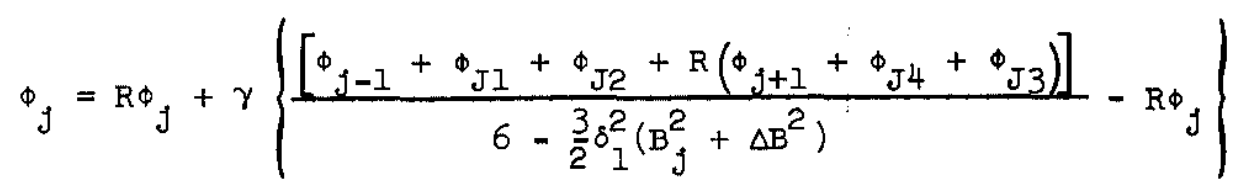

In the iteration procedure, an extrapolation is made on the change in buckling, $\Delta B^{2}$, to speed convergence to critical.

The mesh size has been limited to a maximum of 817 points in the $R-\theta$ plane and a maximum of 16 horizontal levels, or a total of 13,072 points. Since each polnt has a flux and buckling value assoclated with 1 t, this 1 s the maximum number of polnts that can be handled by the 32,000-word core storage in the IBM 704 computer.

\section{Computer Code}

Input for a problem is supplied on cards. At the outset the program requires a control card which 1dentifies the type of problem to be run and the input to expect.

The code sets the initial flux to be flat. In practice, this appears to be almost as good as any for the first approximation.

The code requires that buckling be supplied for each level at which the buckling is unique. The buckling for each unique level is supplied in part only. Buckling values are supplied for a ple-shaped sector of the hexagon and then these values are used in the other five sectors. If the desired buckling map is not symmetric, then only those nonsymmetric values need to be supplied additionally in the input.

The resultant buckling map is then placed successively in horizontal planes above this plane up to, but not including the next plane which has a distinct buckling map.

For sequential problems, it is possible to change individual buckling values at any grid point at any level. In the case where a symmetric buckling map has been loaded but variations to this map are required then these changes may be accomplished in the same manner. 
After the buckling is loaded, the flux values are computed for all of the interior grid points using Equation (3) or (4) for three- or twodimensional problems. The calculation progresses over the grid by row-order (left to right) for each level, proceeding upward from level 2.

The buckling is adjusted by varying $\Delta \mathrm{B}^{2}$ until the flux converges within prescribed limits. The results are then written on magnetic tape for printing.

\section{Use of the Code}

The program allows $N$, the number of points along an edge of the reference hexagon, to be as great as 17, and the number of vertical grid points, NLVL, must not exceed 16.

Results may be obtained for reactors with elther hexagonal or clrcular cross sections. Appendix A gives in detall the manner in wh1ch data are prepared.

Computation time for problems on the IBM 704 depends on the number of iterations required for convergence. The number of 1terations required for convergence depends on the value of $\gamma$, the flux extrapolation factor, and on $X T R A P$, the extrapolation factor on the buckling. It takes about 5 hours for 220 iterations when $N$ is 17 and NLVL is 16 . Experience indicates that $\gamma=1.2$ and $400<$ XTRAP $<700$ give good convergence over a wide range of problems.

Computation times on an IBM 704 are shown in the following table. The required time varied from 43 to 255 minutes as $N$ varled from 9 to 17, while the number of horizontal levels was 16. These results show that computation times in minutes are given by

(number of 1terations)(number of non-zero flux points) $\left(1.1 \times 10^{-4}\right.$ )

\section{Problem 1 Problem 2 Problem 3}

$\begin{array}{llll}\text { N } & 9 & 13 & 17 \\ \text { NLVL } & 16 & 16 & 16 \\ \gamma & 1.2 & 1.2 & 1.2 \\ \text { XTRAP } & 700 & 700 & 500 \\ \text { No. of grid points } & 3472 & 7504 & 13072 \\ \text { No. of non-zero fIux points } & 2366 & 5558 & 10094 \\ \text { No. of iterations } & 150 & 161 & 228 \\ \text { TIme, minutes } & 43 & 102 & 255\end{array}$




\section{APPENDIX A - Input Data}

The following input is required. For convenience the mnemonics used on the input data form will be used to designate that data.

$\mathrm{N}$

NLVL

$\delta_{2}$

CONV

$\gamma$

IDENT

CODE

Number of grid points along an edge of the gross hexagon.

This number may not exceed 27.

Number of grid points in the vertical direction.

This number may not exceed 16. (NLVL $=3$ for a

two-dimensional problem)

Horizontal grid spacing in $\mathrm{cm}$.

Vertical grid spacing in $\mathrm{cm}$.

Average absolute deviation allowed per grid point

between successive iterations.

Extrapolation factor for the flux.

Six character alphameric identifications.

Two-diglt code indicating the type of problem to be run.

Twelve types are allowed and are ldentifled below. A refined

Grid is one which is used to approximate a circular cross section by truncating the corners of the hexagon. A refined grid can be utilized when the number of grid points along an edge of the gross grid is 6,9 , or 17 . A gross grid refers to the grid of hexagonal cross section. Types 1 through 6 refers to three-dimensional problems.

Code $=1$. Refined Grid. Normal buckling with no buckling changes.

2. Refined grid. Normal buckling load plus buckling changes.

3. Refined grid. No normal buckling load. Buckling changes only.

4. Gross grid. Normal buckling load with no buckling changes.

5. Gross grid. Normal buckling load plus buckling changes.

6. Gross grid. Buckling changes only. 
Types 7 through 12 refer to two-dimensional problems.

Code $=7$. Refined grid. Normal buckling load. No changes.

8. Refined grid. Normal buckling load with changes.

9. Refined grid. Buckling changes only.

10. Gross grid. Normal buckling load. No changes.

11. Gross grid. Normal buckling load with changes.

12. Gross grid. Buckling changes only.

XTRAP

Extrapolation factor on the buckling added to each grid point to speed convergence.

NORM Number to which flux will be normalized after convergence and before printout.

NSET The number of levels at which unique buckling maps are Introduced plus one.

Input data cards will be described by type.

Card Type 1. One card of this type is required. Data appearing on this card have all been prevlously described. Decimal locations are indicated for $\delta_{1}, \delta_{2}$, CONV, and $\gamma$.

Card Type 2. This type card is required only if a normal buckling map is submitted. None is submitted if only buckling changes are supplied.

The number appearing on the card is the number of entries on the succeeding card (type 3). This is the number of levels at which there is a unique buckling map supplied plus one.

Card Type 3. This type card is likewise required only if a normal buckling map is submitted.

The numbers appearing on the card are the vertical grid numbers at which a new buckling map appears. The first entry is always 02 ; the last entry is always NLVL. No intermediate numbers are required but if the buckling is not uniform vertically, then each level at which a new map 

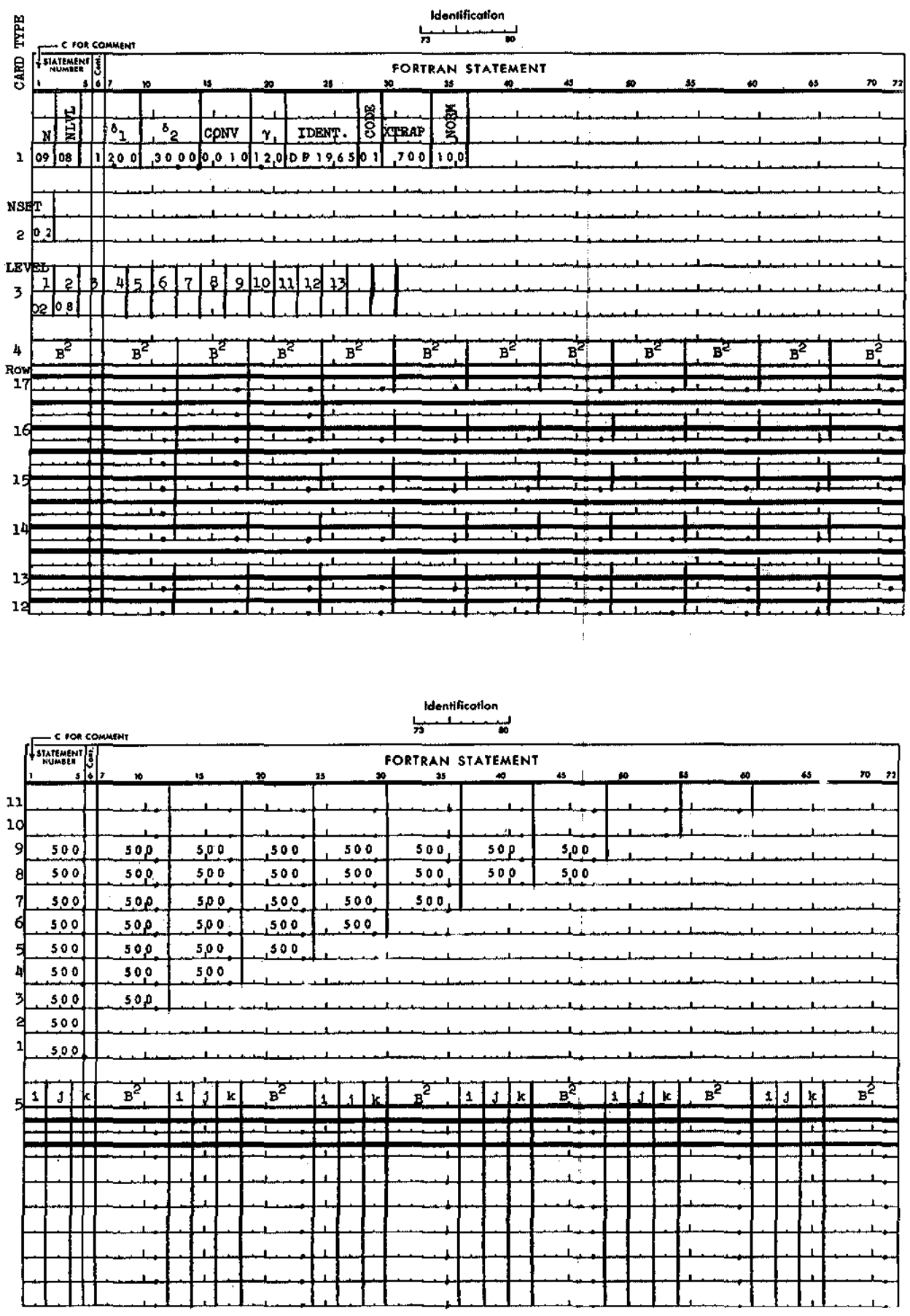
is to be introduced must be listed in order between these two entries.

Since $N L V L=3$ for a two-dimensional problem, this card will contain two numbers only, namely 02 and 03. The reason that two-dimensional problems are treated in this fashion is that the buckling is loaded as though it were a three-dimensional problem.

Card Type 4. If a symmetric buckling map is to be loaded, then $\mathrm{N}$ cards must be supplied for each level at which a new symmetric buckling map is to be loaded. Buckling must be supplied for the gross grid regardless of whether the grid is gross or refined. To prepare the required $\mathrm{N}$ cards, choose row $\mathrm{N}$ as your beginning row. This row will have $\mathrm{N}-1$ entries.

To 1llustrate, let $\mathrm{N}$ be 5 . Choose a sector of the hexagon as Indicated below, where the buckling values are indicated above the grid points.

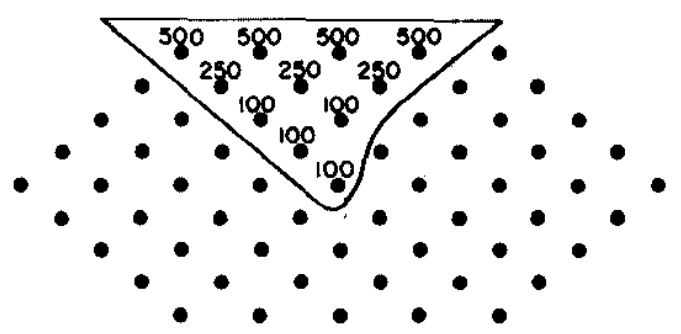

Buckling values are entered on the input sheet starting with row 5. It will have four entries each equal to 500.0. Row 4 will have three entries each equal to 250.0 . Row 3 will have two entries of 100.0. Both row 2 and row 1 will have one entry equal to 100.0 .

Card Type 5. This type is required only if modifications to the symmetric buckling map or to the buckling map of the preceding problem 
is required. Speciflc buckling changes are loaded six per card. Each change is designated as follows:
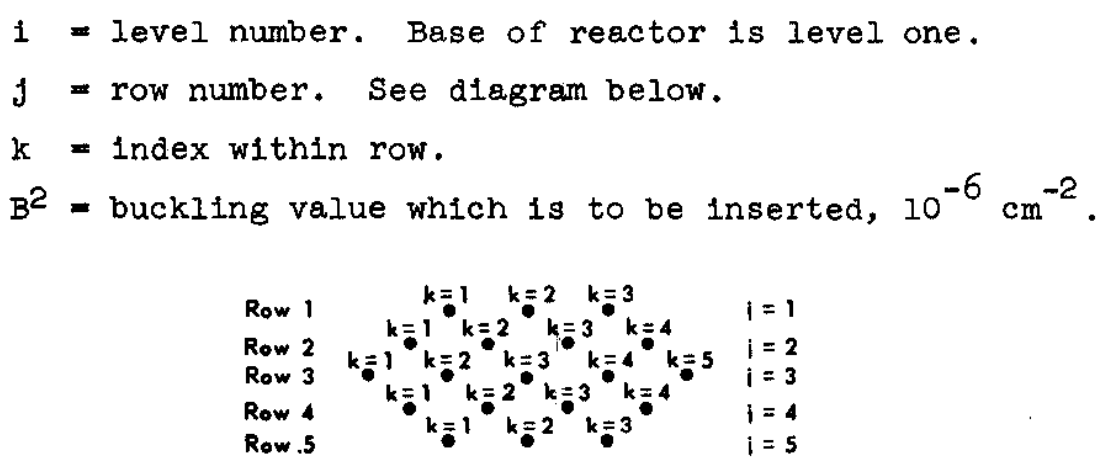

It should be noted that row $I$ is the boundary row where the flux is held to zero. Also, the Index within a row, $k$, is always determined with respect to the gross grid. Buckling changes are terminated by entering on the last card of type $5,1=j=k=99$ for the last buckling entry.

\section{Sample Output}

The output for a sample problem is shown on the following pages for a reactor lattice with eight horizontal levels and the radial grid defined by nine points along the edge of the gross hexagon. 
HEXLAX FLUX

ND. OF 1 TER. $=101$

BUCKLING ADOED= 512.46

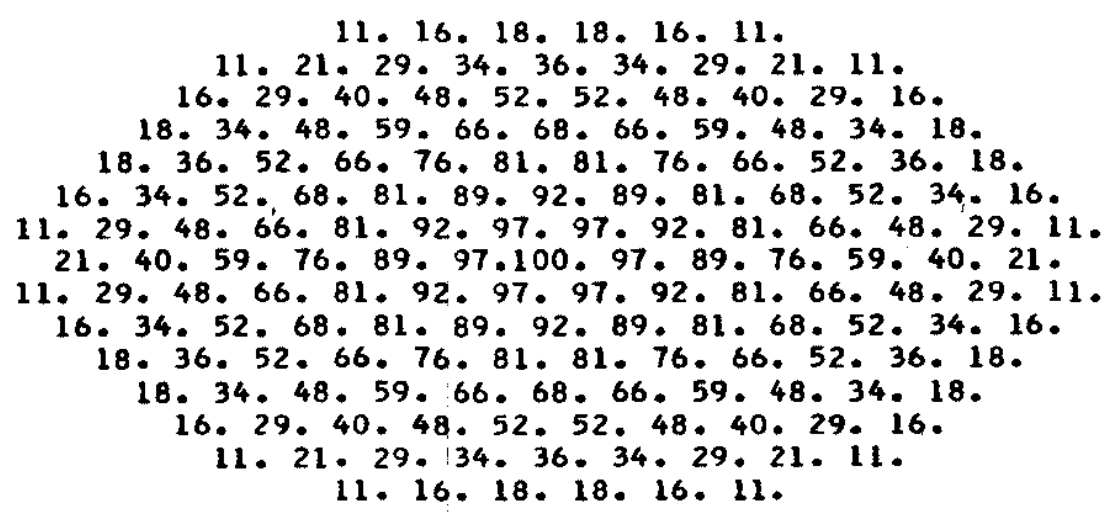

CONVERGENCE CRIT $=.0010$ EXTRAPOLATION $=1.20$ B SQ. EXTRAP $=700$.

PROBLEM NO. DP1965 LEVEL NO. 4

HEXLAX FLUX

NO. OF I TER. $=101$

BUCKLING ADDED $=512.46$

$11.16 \cdot 18,18,16 \cdot 11$.

$11.21 .29 .34,36,34.29,21,11$.

16. 29.40 .48 .52 .52 .48 .40 .29 .16$. 18. $34.48 .59,66.68,66,59,48,34,18$. 18. 36. 52.66 .76 .81 .81 .76 .66 .52 .36 .18$. 16. 34. 52. $68: 81,89.92,89,81,68,52,34.16$. 11. 29.48 .66 .81 .92 .97 .97 .92 .81 .66 .48 .29 .11$. 21. $40.59,76,89,97.100,97,89,76,59,40,21$.

11. 29. 48.66 .81 .92 .97 .97 .92 .81 .66 .48 .29 .11$. 16. 34. 52, 68, 81,89.92,89,81, 68, 52, $34,16$.

$18.36 .52 \cdot 66 \cdot 76.81 .81 \cdot 76 \cdot 66,52.36 \cdot 18$.

$18.34 .48 .59 .66 .68 .66,59.48,34.18$. 16. 29.40 .48 .52 .52 .48 .40 .29 .16$.

11. $21.29,34,36,34 \cdot 29,21 \cdot 11$.

11. 16.18 .18 .16 .11 .

CONVERGENCE CRIT $=.0010$ EXTRAPOLATION $=1.20$ B SQ. EXTRAP $=700$.

PROBLEM NO. DP1965

LEVEL NO. 5 
HEXLAX FLUX

NO. OF ITER $=101$

BUCKLING ADDED $=512.46$

$$
\begin{aligned}
& \text { 9. 13.14.14.13.9. } \\
& \text { 9. } 17.24 .27 .29 .27 .24 .17 .9 . \\
& 13.24 \cdot 32,39,42,42 \cdot 39,32 \cdot 24 \cdot 13 . \\
& \text { 14. 27. 39. } 47.53 .55 .53 .47 .39 .27 .14 . \\
& \text { 14. 29. } 42.53 .61 .65 .65,61.53,42,29.14 . \\
& \text { 13. } 27.42 .55 .65 .71 .73 .71 .65 .55 .42 .27 .13 . \\
& \text { 9. 24. 39. 53.65.73.78, 78, 73,65.53.39. 24. 9. } \\
& \text { 17. 32. } 47.61 .71 .78 .80 .78 .71 .61 .47 .32 .17 \text {. } \\
& \text { 9. 24. 39. 53.65. 73. 78. 78.73.65. 53. 39. 24. 9. } \\
& 13.27 .42 .55 .65 .71 .73 .71 .65 .55 .42 .27 .13 . \\
& 14.29 .42 .53 .61 \cdot 65.65 .61 .53 .42 .29,14 . \\
& \text { 14. } 27.39 .47 .53 .55 .53 .47 .39 .27 .14 . \\
& \text { 13. } 24 \cdot 32 \cdot 39.42 \cdot 42 \cdot 39 \cdot 32 \cdot 24 \cdot 13 . \\
& 9.17 .24 .27 .29 .27 .24 .17 .9 . \\
& \text { 9. 13. 14. 14. 13. } 9 .
\end{aligned}
$$

CONVERGENCE CRIT $=.0010$ EXTRAPOLATION $=1.20 \quad$ B SQ. EXTRAP $=700$.

PROBLEM NO. DP1965 LEVEL NO.: 6

HEXLAX FLUX

NO. OF ITER. $=101$

BUCKLING ADDED $=512.46$

$$
\begin{aligned}
& \text { 5. 9. } 13.75 .16 .15 .13 .9 .9 .5 . \\
& \text { 7. } 13.18,21 \cdot 23,23,21,18,13.7 . \\
& \text { 8. 15. } 21,26,29,30,29,26,21,15 \cdot 8 . \\
& \text { 8. } 16.23 .29 .34 .36 .36 \cdot 34.29 .23 .16 .8 .
\end{aligned}
$$

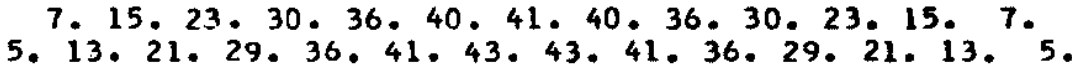

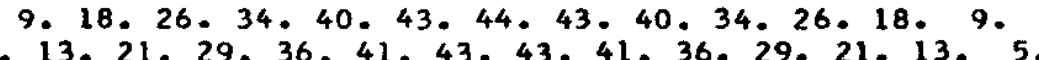

$$
\begin{aligned}
& \text { 8. 16. } 23.29,34.36 .36 .34 .29 .23 .16 .8 . \\
& \text { 8. } 15.21 \cdot 26 \cdot 29.30,29 \cdot 26 \cdot 21 \cdot 15 \cdot 8 . \\
& \text { 7. } 13.18 .21 \cdot 23 \cdot 23 \cdot 21 \cdot 18 \cdot 13 \cdot 7 . \\
& \text { 5. 9. 13. 15. 16.15.13.9.9. } \\
& \text { 5. 7. 8. 8. 7. } 5 .
\end{aligned}
$$

CONVERGENCE CRIT $=.0010$ EXTRAPOLATION $=1.20 \quad$ B SQ. EXTRAP $=700$.

PROBLEM NO. OP1965 LEVEL NO. 7 
HEXLAX B SQD

NO. OF ITER $=101$

BUCKLING ADDED $=512.46$

\author{
$500 \cdot 500 \cdot 500 \cdot 500 \cdot 500 \cdot 500$. \\ $500 \cdot 500 \cdot 500 \cdot 500.500 .500 .500 .500 .500$ \\ 500.500 .500 .500 .500 .500 .500 .500 .500 .500 . \\ 500.500 .500 .500 .500 .500 .500 .500 .500 .500 .500 . \\ 500.500 .500 .500 .500 .500 .500 .500 .500 .500 .500 .500 . \\ $500.500 .500 \cdot 500.500 .500 .500 .500 .500 .500 .500 .500 .500$. \\ 500.500 .500 .500 .500 .500 .500 .500 .500 .500 .500 .500 .500 .500 . \\ $500 \cdot 500 \cdot 500 \cdot 500.500 \cdot 500.500 .500 .500 .500 .500 .500 .500$. \\ 500.500 .500 .500 .500 .500 .500 .500 .500 .500 .500 .500 .500 .500 . \\ $500 \cdot 500.500 \cdot 500.500 .500 .500 .500 .500 .500 .500 .500 .500$. \\ 500.500 .500 .500 .500 .500 .500 .500 .500 .500 .500 .500 . \\ 500.500 .500 .500 .500 .500 .500 .500 .500 .500 .500 . \\ 500.500 .500 .500 .500 .500 .500 .500 .500 .500 . \\ $500 \cdot 500 \cdot 500 \cdot 500 \cdot 500.500 \cdot 500.500 .500$. \\ $500 \cdot 500 \cdot 500 \cdot 500 \cdot 500 \cdot 500$.
}

\author{
CONVERGENCE CRIT $=.0010$ EXTRAPOLATION $=1.20$ B SQ. EXTRAP $=700$. \\ PROBLEM NO. DP1965 LEVEL NO. 2
}

HEXLAX B SQD

NO. OF ITER. $=101$

BUCKLING ADDED $=512.46$ $\begin{array}{rlrl}\text { CONVERGENCE CRIT }= & .0010 & \text { EXTRAPOLATION }=1.20 & \text { B SO. EXTRAP }=700 . \\ \text { PRCBLEM NO. DPI965 } & \text { LEVEL NO. } 3\end{array}$

$-18-$ 
HEXLAX B SQD

NO. OF ITER $=101$

BUCKLING ADDED $=512.46$

\author{
$500.500 .500 \cdot 500.500 .500$ \\ $500 \cdot 500 \cdot 500 \cdot 500 \cdot 500 \cdot 500.500 .500 .500$ \\ 500.500 .500 .500 .500 .500 .500 .500 .500 .500 . \\ $500.500 .500 \cdot 500.500 .500 .500 .500 .500 \cdot 500.500$ \\ 500.500 .500 .500 .500 .500 .500 .500 .500 .500 .500 .500 . \\ $500 \cdot 500 \cdot 500.500 .500 .500 .500 .500 .500 .500 .500 .500 .500$. \\ 500.500 .500 .500 .500 .500 .500 .500 .500 .500 .500 .500 .500 .500 . \\ 500.500 .500 .500 .500 .500 .500 .500 .500 .500 .500 .500 .500 . \\ 500.500 .500 .500 .500 .500 .500 .500 .500 .500 .500 .500 .500 .500$. \\ 500.500 .500 .500 .500 .500 .500 .500 .500 .500 .500 .500 .500 . \\ 500.500 .500 .500 .500 .500 .500 .500 .500 .500 .500 .500 . \\ $500.500 .500 \cdot 500 \cdot 500.500 .500 .500 .500 .500 .500$. \\ 500.500 .500 .500 .500 .500 .500 .500 .500 .500 \\ $500 \cdot 500.500 .500 .500 \cdot 500.500 .500 .500$. \\ 500.500 .500 .500 .500 .500 .
}

HEXLAX B SQD

NO. OF ITER $=101$

BUCKLING ADDED $=512.46$

\author{
$500.500 .500 \cdot 500 \cdot 500.500$ \\ $500 \cdot 500.500 \cdot 500,500.500 .500 .500 .500$ \\ 500.500 .500 .500 .500 .500 .500 .500 .500 .500 . \\ 500.500 .500 .500 .500 .500 .500 .500 .500 .500 .500 . \\ 500.500 .500 .500 .500 .500 .500 .500 .500 .500 .500 .500 . \\ 500.500 .500 .500 .500 .500 .500 .500 .500 .500 .500 .500 .500 . \\ 500.500 .500 .500 .500 .500 .500 .500 .500 .500 .500 .500 .500 .500 . \\ $500.500 \cdot 500.500 \cdot 500.500 .500 .500 \cdot 500 \cdot 500 \cdot 500 \cdot 500.500$. \\ 500.500 .500 .500 .500 .500 .500 .500 .500 .500 .500 .500 .500 .500 . \\ $500.500 \cdot 500.500 .500 .500 .500 .500 .500 .500 .500 .500 .500$. \\ 500.500 .500 .500 .500 .500 .500 .500 .500 .500 .500 .500 . \\ 500.500 .500 .500 .500 .500 .500 .500 .500 .500 .500 . \\ $500.500 \cdot 500.500 .500 \cdot 500.500 .500 \cdot 500.500$ \\ $500 \cdot 500 \cdot 500 \cdot 500.500 .500 .500 .500 \cdot 500$ \\ $500.500 .500 \cdot 500.500 .500$.
}

CONVERGENCE CRIT $=.0010$ EXTRAPOLATION $=1.20 \quad$ B SQ. EXTRAP $=700$
LEVEL NO. 5 
HEXLAX B SQD

NO. OF ITER $=101$

BUCKLING ADDED $=512.46$

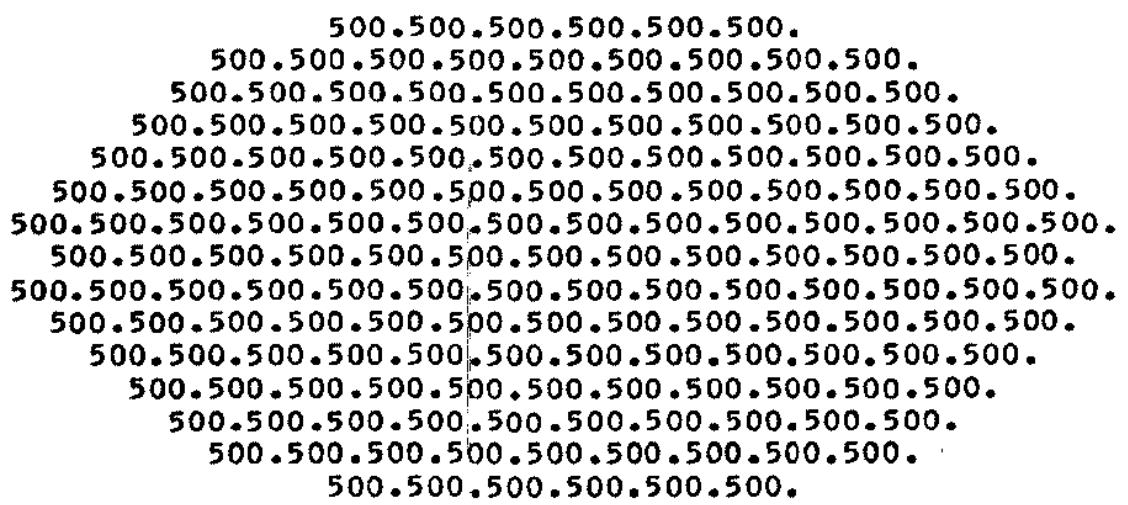

$500 \cdot 500.500 \cdot 500 \cdot 500.500$ $500 \cdot 500 \cdot 500 \cdot 500 \cdot 500 \cdot 500 \cdot 500 \cdot 500 \cdot 500$ 500.500 .500 .500 .500 .500 .500 .500 .500 .500$. $500.500 .500 .500 \cdot 500.500 .500 .500 .500 .500 .500$. $500 \cdot 500 \cdot 500 \cdot 500 \cdot 500.500 .500 .500 .500 .500 .500 .500$. $500.500 \cdot 500.500 .500 .500 .500 .500 .500 .500 .500 .500 .500$. 500.500 .500 .500 .500 .500 .500 .500 .500 .500 .500 .500 .500 .500 . 500.500 .500 .500 .500 .500 .500 .500 .500 .500 .500 .500 .500 . $500.500 .500 .500 .500 \cdot 500.500 .500 .500 .500 .500 .500 .500 .500$. 500.500 .500 .500 .500 .500 .500 .500 .500 .500 .500 .500 .500 . 500.500 .500 .500 .500 .500 .500 .500 .500 .500 .500 .500 . $500.500 \cdot 500 \cdot 500 \cdot 500.500 .500 \cdot 500.500 .500 .500$. $500.500 .500 \cdot 500 \cdot 500.500 .500 .500 .500 .500$. $500 \cdot 500 \cdot 500 \cdot 500.500 \cdot 500 \cdot 500 \cdot 500.500$ $500.500 .500 \cdot 500.500 .500$.

\author{
CONVERGENCE CRIT $=.0010$ EXTRAPOLATION $=1.20$ B SQ. EXTRAP $=700$. \\ LEVEL NO. 6
}

HEXLAX B SQD

NO. OF ITER. $=101$

BUCKLING ADDED $=512.46$
$500 \cdot 500.500 \cdot 500.500 .500$ $500.500 .500 \cdot 500.500 .500 \cdot 500.500 .500$ 500.500 .500 .500 .500 .500 .500 .500 .500 .500 $500.500 .500 \cdot 500 \cdot 500 \cdot 500.500 \cdot 500 \cdot 500 \cdot 500.500$. 500.500 .500 .500 .500 .500 .500 .500 .500 .500 .500 .500 . 500.500 .500 .500 .500 .500 .500 .500 .500 .500 .500 .500 .500 . 500.500 .500 .500 .500 .500 .500 .500 .500 .500 .500 .500 .500 .500 . $500.500 \cdot 500.500 .500 .500 .500 .500 .500 .500 .500 .500 .500$. 500.500 .500 .500 .500 .500 .500 .500 .500 .500 .500 .500 .500 .500 $500 \cdot 500 \cdot 500 \cdot 500 \cdot 500 \cdot 500 \cdot 500 \cdot 500 \cdot 500 \cdot 500 \cdot 500.500 .500$. 500.500 .500 .500 .500 .500 .500 .500 .500 .500 .500 .500 . $500.500 .500 \cdot 500 \cdot 500.500 .500 .500 .500 .500 .500$. $500.500 .500 \cdot 500.500 .500 .500 .500 .500 .500$. 500.500 .500 .500 .500 .500 .500 .500 .500 . 500.500 .500 .500 .500 .500 .

CONVERGENCE CRIT $=.0010 \quad$ EXTRAPOLATION $=1.20 \quad$ B SQ. EXTRAP $=700$

PROBLEM NO. DP1965 LEVEL NO. 7 


\section{APPENDIX C - FORTRAN Source Code}

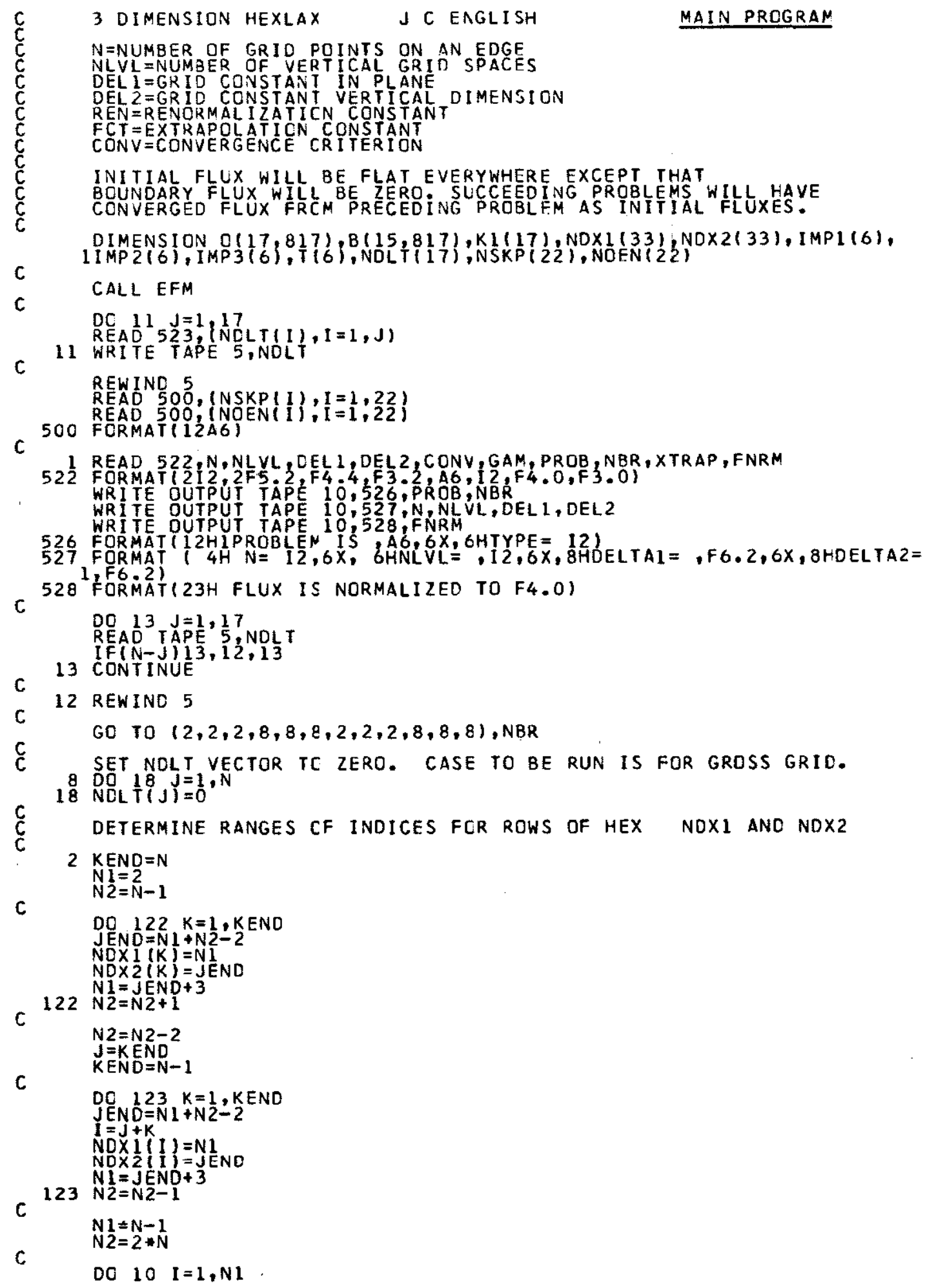

C

$N 2=N 2-2$

$\mathrm{K} E N \mathrm{D}=\mathrm{N}-1$

DO $123 \mathrm{~K}=1$, KEND $J E N D=N 1+N 2-2$ $I=\mathrm{J}+\mathrm{K}$ NDX $1(1)=N 1$ $\mathrm{NI}=\mathrm{JEND}+3$

c

$123 N 2=N 2-1$

C

$N 1=N-1$

C $\quad \mathrm{N} 2=2 * \mathrm{~N}$

DO $10 I=1, N 1$ 


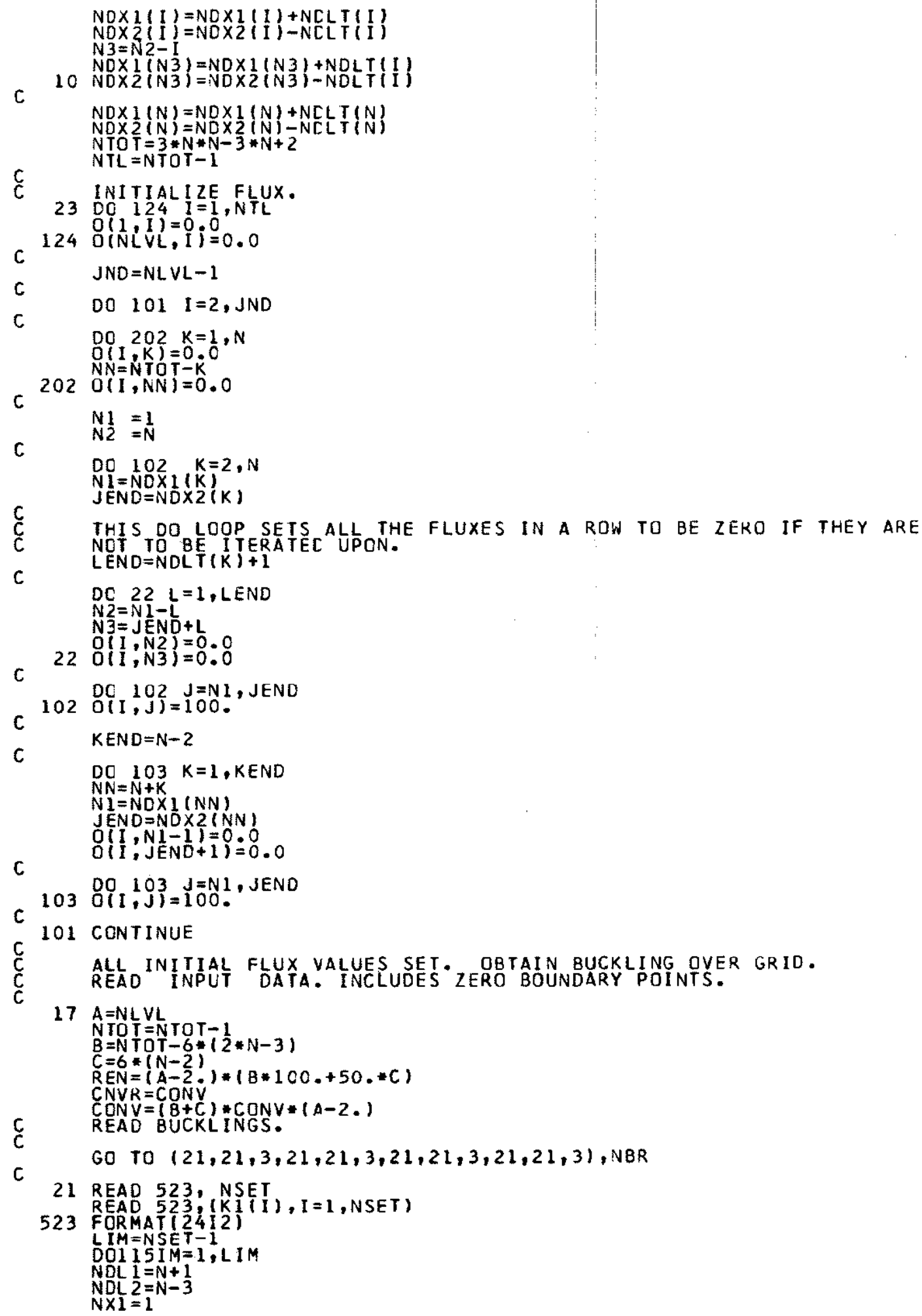

C

103 DO $103 \mathrm{~J}=\mathrm{N} 1$, JEND

101 CONTINUE

C ALL INITIAL FLUX VALUES SET OBTAIN BUCKLING OVER GRID.

$17 \mathrm{~A}=\mathrm{NL} V \mathrm{~L}$ NTO $T=N$ TOT -1 


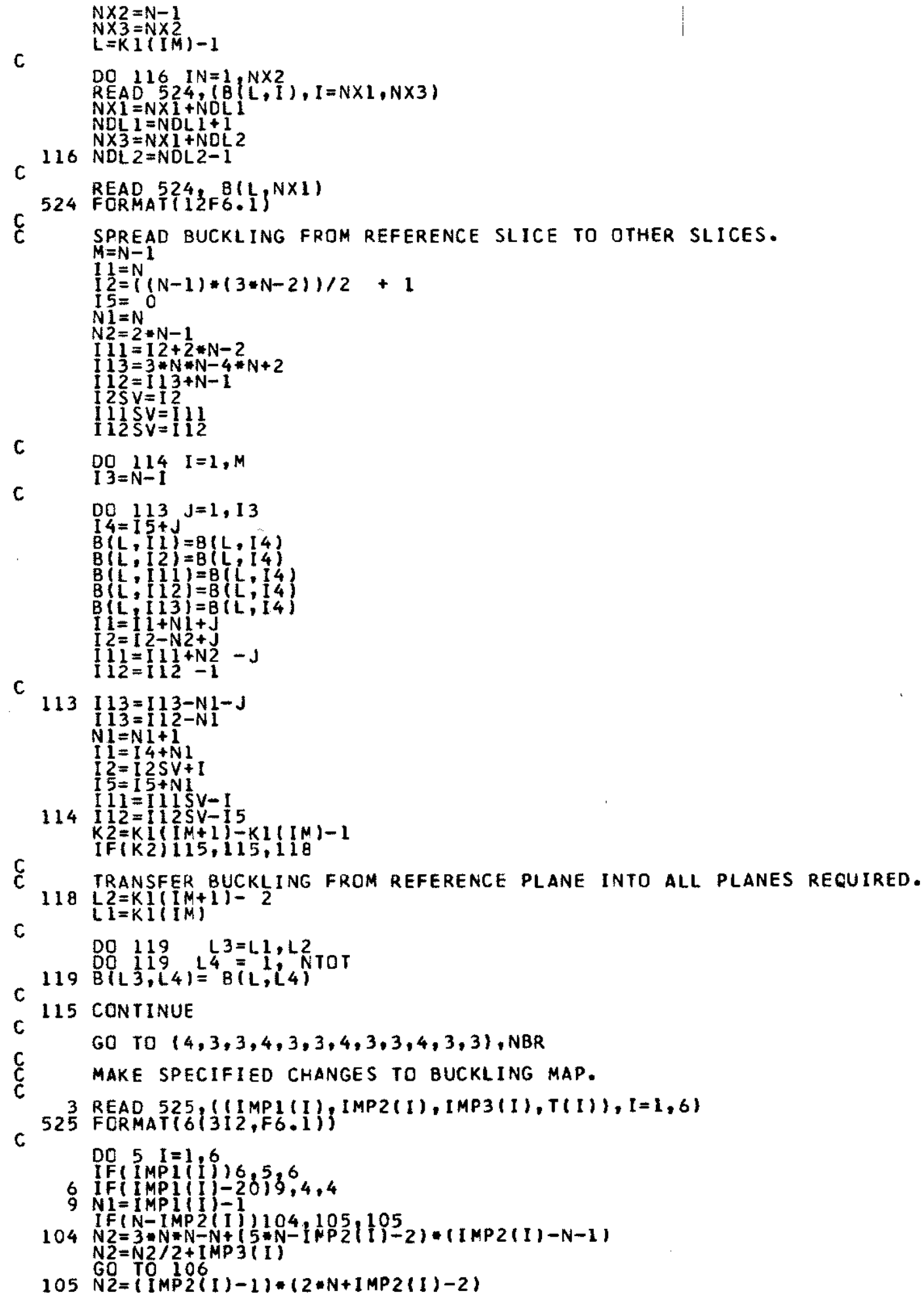

C

$$
\text { DO } 114 \quad I=1, M
$$

DO $113 \mathrm{~J}=1,13$

$I 4=I 5+J$

$B(L, I I)=B(L, I 4)$

$B(L ; I 2)=B(L ; 14)$

$B(L, I 11)=B(L, 14)$

$B(L ; 1)=B(L, I 4)$

$\mathrm{I} \mathbf{i}=\mathbf{I} \mathbf{i}+\mathrm{N} \mathbf{i}+\mathbf{J}$

$I 2=I 2-N 2+$

$1 \frac{1}{1}=1 \frac{1}{1}=1 \frac{1}{2}-1-J$

C

$113 \mathrm{I} 13=\mathrm{I} 13-\mathrm{N} 1-\mathrm{J}$

$I 13=I 12-N I$

$\mathrm{N} 1=\mathrm{N} 1+1$

$I 1=I 4+N 1$

$I 2=I 2 S V+1$ $Y=15+N 1$

114 I $11=1112 S V-I$

$K 2=K I(I M+1)-K I(I M)-1$

c IF(K2)115,115,118

C 118 TRANSFER BUCKLING FROM REFERENCE PLANE INTO ALL PLANES REQUIRED.

C $L 2=K I(I M+)$

c

$$
\text { DO } 119, L \frac{1}{3}=L 1, L 2
$$




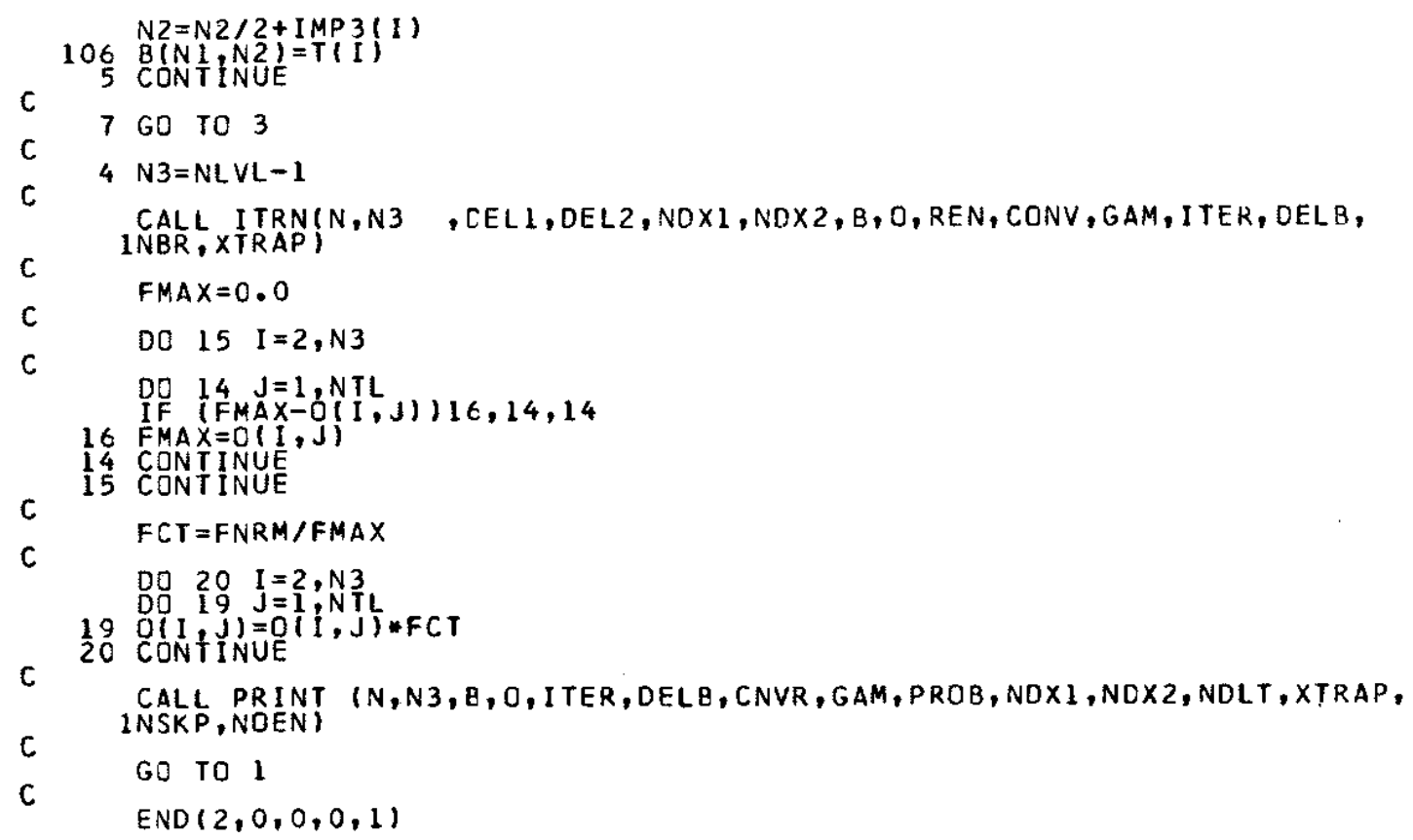
SUBROUTINE IIRNIN,N3 ,DEL1, DEL2, NDX1, NDX2, B, O, REN,CONV,GAM, ITER, IDELB, NBR, XTRAP)

DIMENSION NDX1(33), NDX2(33),B(15,817),0(17,817)

INITIALIZE ITERATION $T=R=0$
$R=1,0$

$A 1=D E L 2 * D E L 2$

$A 2=1.5$ \#EL $1: D E L 1$

$A 4=A T * A 2 * . C 00001$

C $D E L B=0.0$

GO TO $(9,9,9,9,9,9,3,3,3,3,3,3), N B R$

C 3 A2 $=A 2 * .000001$

9 SUM $=0.0$

C

$\mathrm{DO} 16, \mathrm{I}=2, \mathrm{~N} 3$

$N 2=N+1$

$c$

DO $12 K=2, K E N D$

$N I=N D \times I(K)$

JEND $=N D \times 2(K)$

DON $1, J=N 1$, JEND

$J 1=J-N 2+1$

$J 2=J 1-1$

$J 3=J+N 2$
$J 4=J 3+1$

$c$

GO TO $(10,10,10,10,10,10,14,14,14,14,14,14), N B R$

c

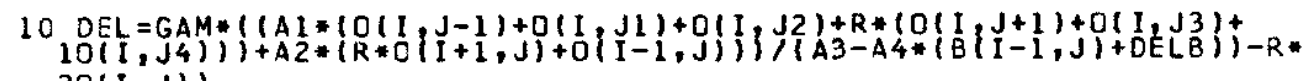
$20(1, J))$ 


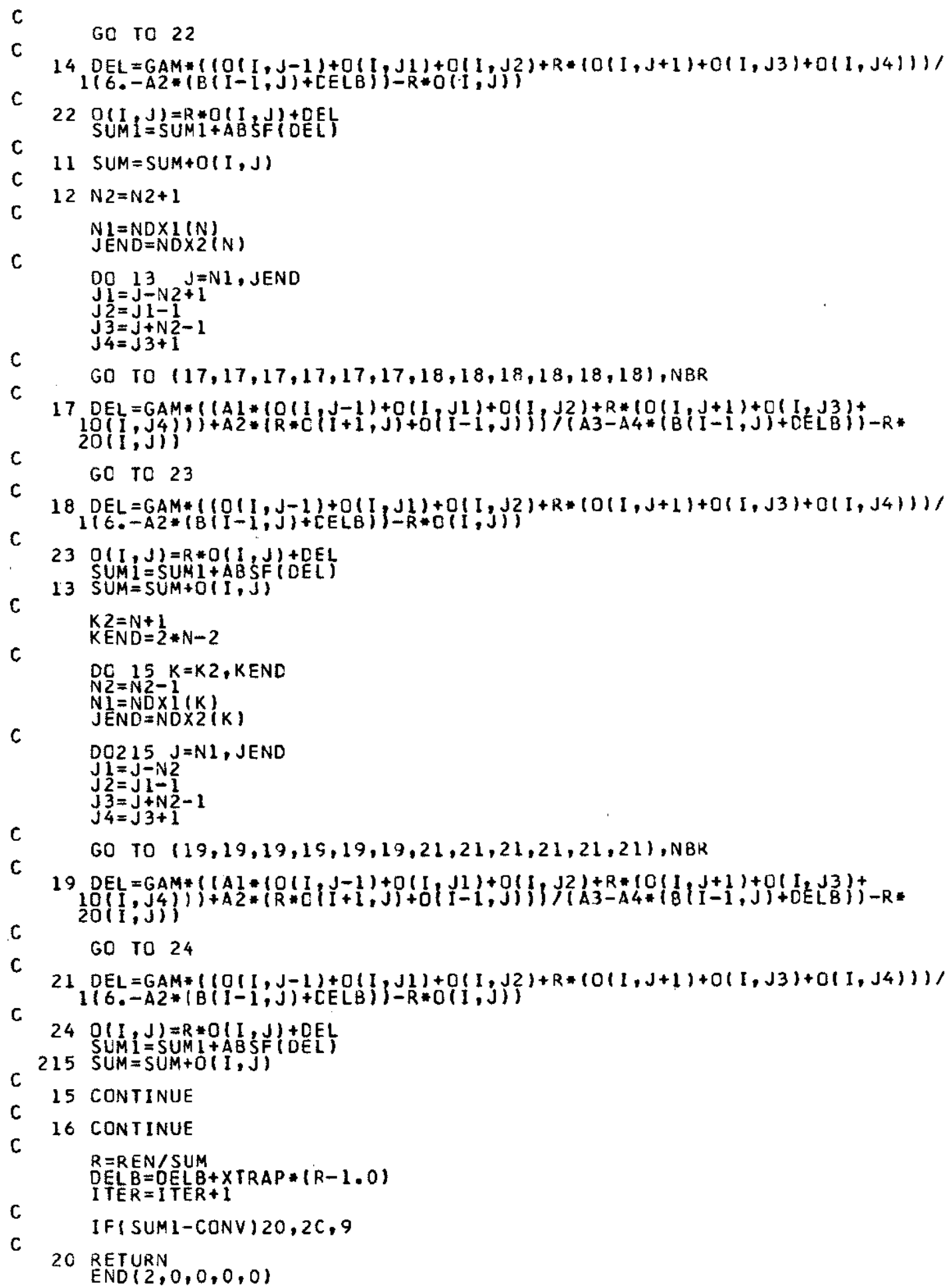




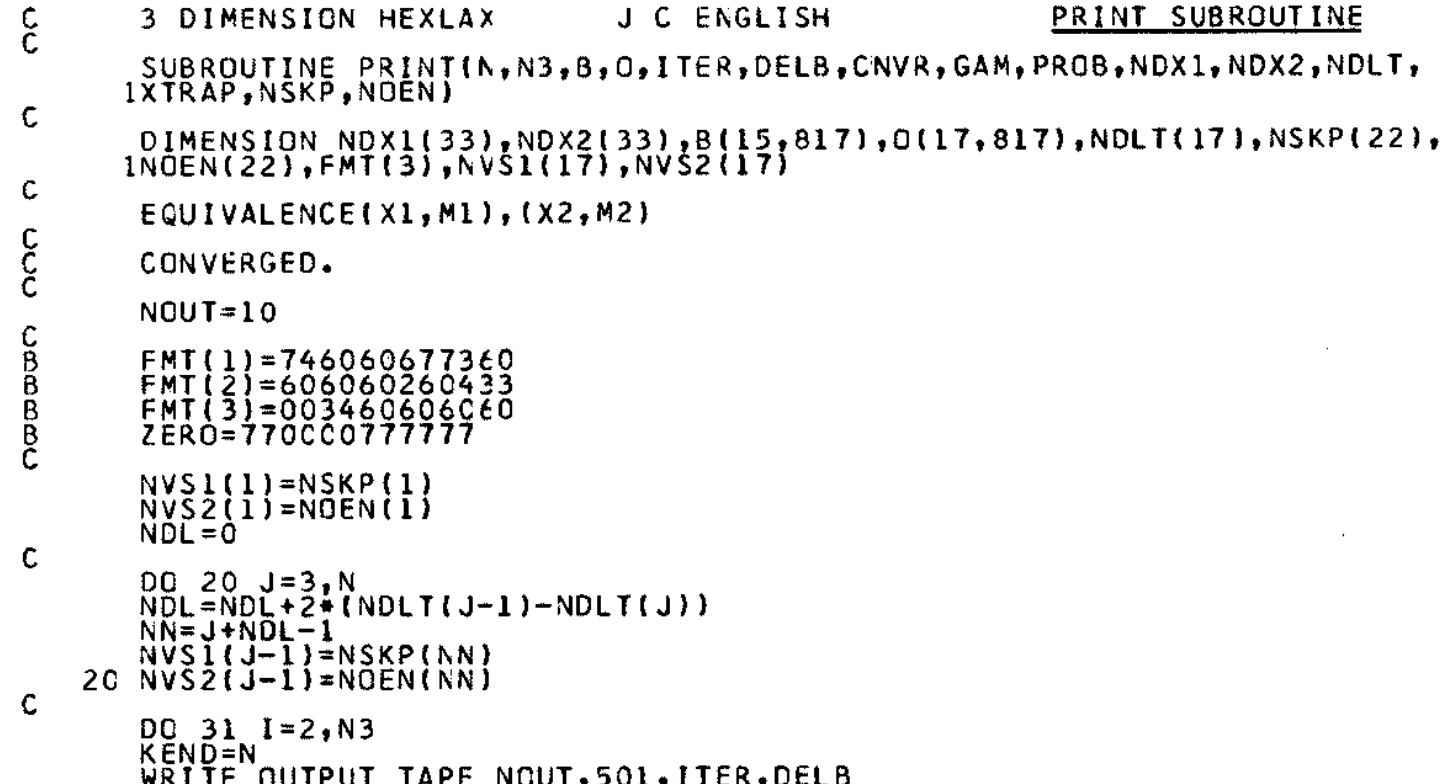




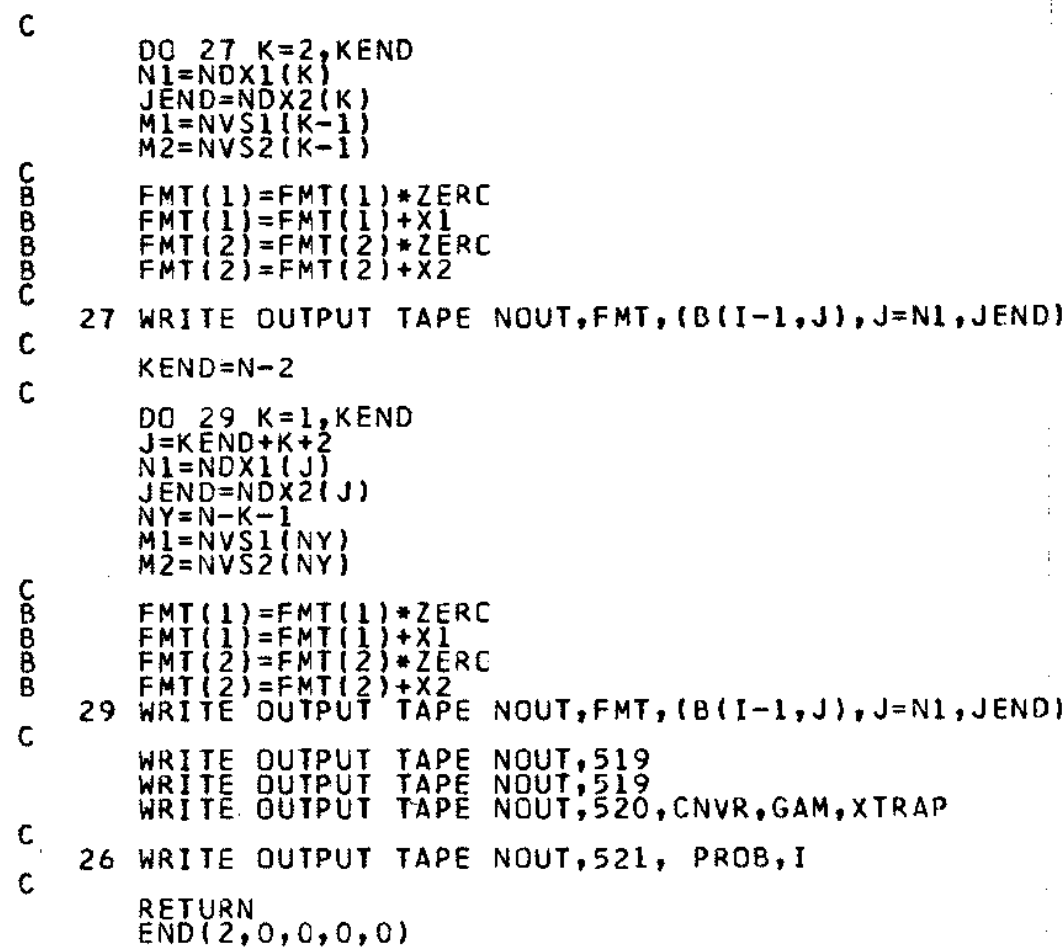

